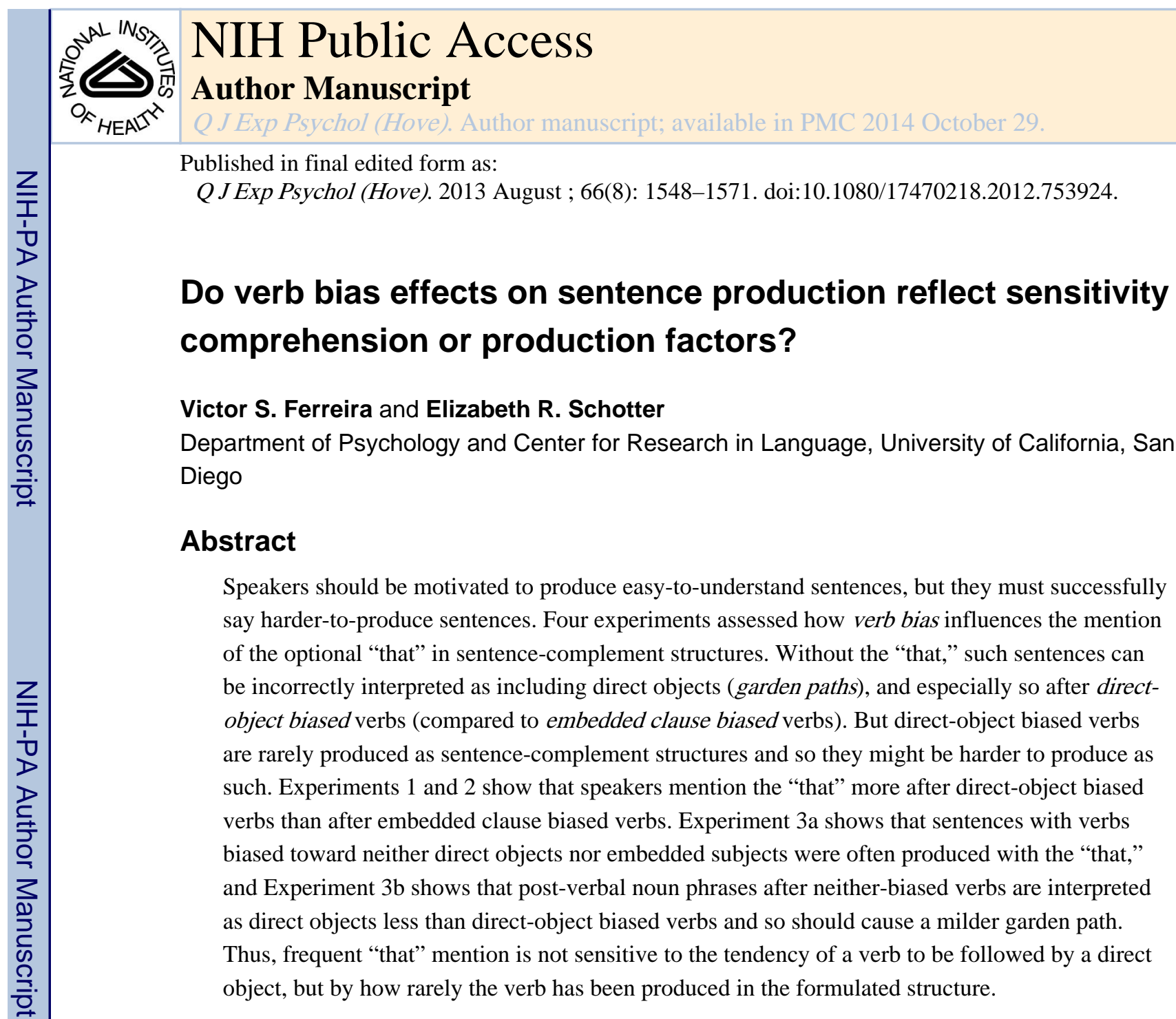

\title{
Keywords
}

Language production; communication; ambiguity; frequency

Speakers speak to be understood. Presumably, the easier a sentence is to understand, the more likely it is that it will be understood successfully. So, given a choice and all else equal, speakers should produce sentences that will be easier for their addressees to understand.

But all else is not always equal. The mechanisms responsible for language production, like the mechanisms responsible for any behaviour, are subject to cognitive demands. One powerful demand is effort: Some behaviours are easier to perform than others. And so speakers might produce particular sentence choices rather than others not in service of any goal to be better understood, but instead to perform an easier rather than a harder behaviour.

Consider a sentence like "The talented photographer accepted (that) the money could not be spent." Sentences like these, termed sentence complement structures, are grammatical whether speakers mention or omit the "that" (termed a complementizer). Furthermore, the

Address for correspondence: Victor Ferreira, Department of Psychology, University of California, San Diego, 9500 Gilman Drive, La Jolla, CA 92093-0109, USA, Voice: +1-858-534-6303, Fax: +1-858-534-7190, vferreira@ ucsd.edu. 
presence or absence of the "that" has little (Bolinger, 1972; Thompson \& Mulac, 1991; Yaguchi, 2001) or no effect on the overall meaning of the sentence. But, research suggests that the mention or omission of the "that" can have other effects. One such effect is about understandability: The "that" can make some sentences easier to understand. Another such effect is about cognitive demands: The "that" can accompany sentences that are harder to produce. Each of these is discussed in turn.

\section{Garden path sentences}

Consider the sentence beginning, "The talented photographer accepted the money..." At this point in the sentence, a comprehender is very likely to interpret the noun phrase "the money" as a direct object, as in a sentence like "The talented photographer accepted the money gleefully." This is because at this intermediate point in the sentence, the interpretation where "the money" is a direct object is simpler (F. Ferreira \& Henderson, 1990) and more common (Trueswell, Tanenhaus, \& Kello, 1993), and so comprehenders are likely to interpret the sentence that way. But in the actual sentence, "the money" is not a direct object; it's the subject of the embedded clause "the money could not be spent yet." This means that upon comprehending "could," the comprehender must revise his or her original interpretation so that "the money" is understood to be an embedded subject -- the subject of an embedded clause.

This processing sequence whereby a comprehender initially interprets a sentence incorrectly and then revises it is termed a garden path. Garden paths represent the difficulties that comprehenders experience as they understand sentences, and as a result, they have been heavily studied in the psycholinguistic literature (because the kinds of garden paths comprehenders are vulnerable to and how they overcome them reveals the nature of the mechanisms responsible for sentence comprehension). Because garden paths pose difficulties for comprehenders, speakers who want to be understood might avoid producing them. Indeed, in sentence-complement structures, this is easily done: If a speaker mentions the optional "that," the garden path is eliminated ("The talented photographer accepted that the money..." cannot be interpreted with "the money" as a direct object). So this raises the interesting possibility that speakers might mention the "that" specifically in sentences that would otherwise cause especially difficult garden paths.

The current research examines how verb biases influence speakers' sentence-production choices, specifically whether speakers mention the "that" or not in sentence-complement structures. Here, verb bias refers to how frequently the main verb in a sentence-complement structure is generally produced in sentence-complement structures -- that is, followed by an embedded clause -- versus as a simple transitive sentence -- that is, followed by a direct object. Main verbs that are frequently followed by embedded clauses and rarely followed by direct objects are termed embedded clause biased verbs and main verbs that are frequently followed by direct objects and rarely followed by embedded clauses are termed direct-object biased verbs. (Although we describe verb bias as though it is a categorical factor, verbs' biases can in fact vary continuously. That is, a verb may rarely, sometimes, or often take an embedded clause, or it may rarely, sometimes, or often take a direct object. Analyses below will consider verb bias categorically, as well as continuously, defined as how often a 
particular verb is followed by a direct object divided by the sum of how often it is followed by a direct object plus embedded subject.) Important here is that the bias of the main verb in a sentence-complement structure affects how severely the garden path within that structure disrupts comprehension. Specifically, Garnsey, Pearlmutter, Myers, and Lotocky (1997) showed that sentence-complement structures with direct-object biased main verbs generally caused bigger garden path effects than sentence-complement structures with embedded clause biased main verbs. This difference arises because direct-object biased main verbs more strongly encourage comprehenders to interpret the noun phrases following them incorrectly as direct objects -- they usually are. But of course, in sentence-complement structures, these noun phrases are embedded subjects. Meanwhile, embedded clause biased main verbs less strongly encourage comprehenders to interpret the noun phrases following them as direct objects, instead encouraging the ultimately correct embedded subject interpretation.

Intriguingly, there is evidence showing that in accordance with this comprehension difference, speakers are more likely to produce the garden-path-eliminating "that" in sentence-complement structures with direct-object biased main verbs than in sentencecomplement structures with embedded clause biased main verbs. Garnsey et al. (1997) normed the verbs they used to determine their biases. To do so, they asked a group of subjects to complete sentence onsets of the form "Karen accepted ," and measured how frequently writers completed the sentences with embedded clauses, direct objects, or some other structure. Of course, when writers completed onsets with embedded clauses, they either included or omitted the "that." Although not directly relevant to Garnsey et al.'s main point, they reported how often subjects included the "that" with an embedded clause completion in sentences with embedded clause versus direct-object biased verbs. They found a difference: Writers' sentence-complement completions with direct-object biased main verbs included the "that" more than their sentence-complement completions with embedded clause biased main verbs. This difference is intriguing because it might show that language production mechanisms in fact choose sentence structures that are easier to understand, in that they insert the "that" more just in those structures that would otherwise be harder to understand. (It is worth noting that the garden path under scrutiny here is relatively mild, so the gains achieved by avoiding them may not be great. But the question here is, given that there is a difference between verbs with different direct object vs. embedded clause biases, is it due to the disruptiveness of the garden path elicited by such structures?)

An implementation of a production strategy whereby speakers mention the "that" to avoid especially disruptive garden paths might begin by having verbs in speakers' production lexicons encode the likelihood that they continue with different arguments. A verb here classified as direct-object biased may encode in the production lexicon that it takes a direct object, say, $75 \%$ of the time and an embedded clause $10 \%$ of the time. This information could then be used to guide the choice to mention the "that"; the greater the direct object likelihood relative to the embedded clause likelihood, the more that production mechanisms will be biased to mention the "that." Such a mechanism could be seen as a production version of an aspect of the constraint-satisfaction model of sentence comprehension presented by McRae, Spivey-Knowlton, and Tanenhaus. (1998). 


\section{Production effort}

Producing a sentence is cognitively demanding. It requires speakers to conceive of a message, choose words that can convey that message, construct a syntactic form that grammatically organises those words and conveys relational information, retrieve the sounds of the ordered words, and then articulate those sounds with an appropriate prosody, all at the same time. Naturally, the extent of these demands varies; some messages can be conveyed with harder to produce sentences than others.

Evidence suggests that when producing sentence-complement structures specifically, speakers mention the optional "that" more in relatively difficult-to-produce sentences. This has been shown mostly through manipulations of the difficulty of retrieving sentence content. V. S. Ferreira and Dell (2000) had speakers produce sentence-complement structures from memory where the embedded subject did or did not repeat the main subject (e.g., "I knew (that) I..." vs "I knew (that) you..."). Embedded subjects that are not repeated should be harder to retrieve than embedded subjects that are repeated. Correspondingly, V. S. Ferreira and Dell found that speakers said the "that" more in sentence-complement structures with embedded subjects that did not repeat main subjects than those that did. Similarly, Jaeger (2010) found that in a natural speech corpus, embedded subjects that referred to the same referent as main subjects were preceded by "that" less. V. S. Ferreira and Firato (2002) had speakers produce sentence-complement structures where the embedded subject was conceptually similar to or conceptually distinct from three noun phrases in the main subject (e.g., "The author, the poet, and the biographer felt (that) the writer..." vs. "...felt (that) the golfer..."). Conceptually similar embedded subjects should be subject to proactive interference, whereby retrieval is hindered by a type of similarity-driven confusion (Keppel \& Underwood, 1962). Correspondingly, V. S. Ferreira and Firato showed that speakers mentioned the "that" more in sentences with the conceptually similar embedded subjects. Furthermore, sentences with conceptually similar embedded subjects were produced with more disfluencies (fillers like "uh" and "um," etc.) than sentences with conceptually dissimilar embedded subjects, and sentences with more disfluencies were produced more with the "that" (see also Jaeger, 2005, 2010) V. S. Ferreira and Hudson (2011) had speakers produce sentence-complement structures as answers to questions. To answer the questions, speakers had to adopt either their own perspective on a situation or their addressees' perspective. Speakers should find it harder to adopt their addressees' perspective than their own, and accordingly, V. S. Ferreira and Hudson found that speakers mentioned the "that" more in answers requiring them to adopt their addressees' perspective (see also Jaeger, 2010, for converging corpus evidence). In sum, a range of evidence suggests that speakers include the optional "that" more when producing more difficult-toproduce sentences.

The verb bias variable introduced above is likely to in part determine the difficulty of producing sentence-complement structures. Verb bias reflects how frequently speakers have produced particular main verbs as particular structures. If a verb is frequently produced as the main verb of a sentence-complement structure, it may be easier to produce that sentence, compared to if a verb is rarely produced as the main verb of a sentence-complement structure. Because direct-object biased verbs are less frequently produced as the main verbs 
of sentence- complement structures, they may be more difficult to produce in such structures, relative to embedded clause biased verbs, which are more frequently produced as the main verbs of sentence-complement structures. We discuss two reasons why the rate with which verbs are produced as sentence-complement structures may affect difficulty of production: Frequency differences, and differences in message formulation.

Frequency is likely among the most heavily investigated factors in the behavioural sciences. Simply put, people are faster, more fluent, and less error prone when executing sequences of behaviour they have performed more frequently, compared to sequences of behaviours they have performed less frequently. This has not been heavily explored in the sentenceproduction domain, but F. Ferreira and Engelhardt (2006) raise the issue and consider two relevant studies. Tannenbaum and Williams (1968) cued speakers to produce active or passive sentences in miniature discourses that sometimes licensed the particular active or passive structure. Relevantly, actives are a much more frequent construction than passives (Svartvik, 1966). Tannenbaum and Williams found that active-licensing discourses tended to elicit actives and passive-eliciting discourses passives, but in no condition were passives produced with faster latencies than actives (the strength of this conclusion is undermined somewhat by the fact that the latency measure included the duration of the utterance itself, and passive sentences have more words and morphemes in them than actives; however, in neutral discourses, actives were produced nearly $1.5 \mathrm{~s}$ faster than passives, a difference likely to be much larger than can be accounted for by passives' additional material). Similarly, F. Ferreira (1994) had speakers produce actives and passives that included verbs that are produced in passives relatively less often versus verbs that are produced in passives more often (though still much less than half the time). When collapsed across verb types, formulation latencies (how long speakers took to indicate they were ready to produce a sentence) were faster for actives than for passive sentences (and here, production latencies were onset latencies and did not include utterance duration). Together, these results suggest that speakers can formulate and articulate a more frequent structure (actives) faster than a less frequent structure (passives), consistent with the possibility that the more frequent structure was easier to produce.

For the sentence-complement structures under scrutiny here, the relevant frequency difference is for a particular structure, contingent on the verb that takes the structure as an argument. Specifically, given a sentence-complement structure, speakers have produced that structure with one set of verbs -- embedded clause biased verbs -- more frequently than with another set of verbs -- direct-object biased verbs. This raises the possibility that the more frequent verb-structure pairing will be easier to produce than the less frequent verb-structure pairing. If so, speakers may say the "that" less in sentence-complement structures with embedded clause biased verbs than in sentence-complement structures with direct-object biased verbs, as a reflection of the relative ease of producing the former compared to the latter.

A closely related result was reported by Gahl and Garnsey (2004). They had speakers produce sentences with embedded clause biased and direct-object biased verbs both as sentence-complement structures (i.e., with an embedded clause) and as transitive structures (i.e., with a direct object). They measured whether speakers reduced the phonology of their 
productions (by deleting the $/ \mathrm{t} /$ or $/ \mathrm{d} /$ ), as well as prosodic properties of the productions. Results showed more deletion of /t/ and /d/ in "bias matching" contexts (when an embedded clause was produced with an embedded clause biased verb or a direct object with a directobject biased verb) than in "bias violating" contexts (when the bias of the verb and the structure produced mismatched). Similarly, bias-matching productions were produced with reduced prosody. Speakers tend to reduce their production of more frequent elements (e.g., Gregory, Raymond, Bell, Fosler-Lussier, \& Jurafsky, 1999). This suggests that the frequency of a produced structure contingent on the bias of the verb produced with that structure can affect production.

Another (not mutually exclusive) reason why speakers may find sentence-complement structures with direct-object biased verbs to be more difficult to produce than sentencecomplement structures with embedded clause biased verbs is due to differences at the level of message formulation (we thank an anonymous reviewer for raising this possibility). Note that in all likelihood, the reason why verbs have the biases they do is because of how speakers tend to use particular verbs to talk about the world. The verb "accept" is directobject biased likely because when speakers talk about accepting, they tend to talk about simple objects rather than entire propositions, and so they will use direct objects; the verb "announce" in contrast is likely used to announce propositions, and so it will more often be followed by an embedded clause. As such, using "accept" to talk about a proposition may fit less well with the meaning of "accept" and what it is used to talk about, as compared to the verb "announce." In turn, this may make it more difficult to formulate sentence-complement structures that use "accept" as the main verb, relative to sentence-complement structures that use "announce" as the main verb; if so, speakers may include the "that" in sentencecomplement structures that have direct-object biased verbs more than in sentencecomplement structures that have embedded clause biased verbs. Note that the possible effect of formulation difficulty on "that" mention is similar to the result reported by V. S. Ferreira and Hudson (2011), where speakers said the "that" in sentence complement structures more when the sentence required adopting their addressees' perspectives compared to when the sentence required adopting their own perspectives -- likely a difference in difficulty of message formulation.

Jaeger (2010) reported an effect similar to the verb-bias effect considered here. He measured how often particular verbs in a speech corpus (the Penn Treebank component of the Switchboard corpus; Godfrey, Holliman, \& McDaniel, 1992) were followed by embedded clauses relative to other construction types (which is like verb bias as described here, except counting only embedded clauses and not direct objects), and showed that the more a verb tended to be followed by an embedded clause, the less likely the "that" was to introduce the embedded clause. Similar effects of omitting optional material have been observed in corpora examining relative clauses (Jaeger, 2006, 2011; Levy \& Jaeger, 2007; Wasow, Jaeger, \& Orr, 2011).

Jaeger positions the results as supporting uniform information density, whereby speakers attempt to spread the informativeness of a sentence evenly across a sentence. If a verb rarely takes an embedded clause, the arrival of that embedded clause is surprising and so highly informative. If a "that" introduces the embedded clause, the arrival of the embedded clause 
is less surprising and so not as informative. Thus, by uniform information density, the "that" serves to reduce the "spike" of information that would have accompanied the arrival of an embedded clause following a verb that is rarely followed by embedded clauses. This fits with the Garnsey et al. (1997) effect reported above, and though different in interpretation, also with the possibility that difficulty affects the mention of the "that."

\section{The present study}

Thus, there are two (non-mutually exclusive) explanations for the possible effect whereby speakers mention the optional "that" more in sentence-complement structures with directobject biased main verbs than in sentence-complement structures with embedded-clause biased main verbs. Such an effect (if it holds in online spoken production like it does in offline norming and in natural corpora) might reflect a tendency to produce sentencecomplement structures with direct-object biased main verbs so that they are easier to understand; or it might reflect that sentence-complement structures with direct-object biased main verbs are harder to produce. Experiment 1 here verified that in spoken production, speakers include the optional "that" more in sentence-complement structures with directobject biased main verbs than in sentence-complement structures with embedded clause biased main verbs. Experiment 2 confirmed that this effect was not an artefact of the task used in Experiment 1.

Then, Experiments $3 \mathrm{a}$ and $3 \mathrm{~b}$ aim to distinguish the two explanations just described, to determine whether speakers say the "that" more in sentence-complement structures with direct-object biased main verbs because they will be easier to understand that way, because they are harder to produce that way, or because of a combination of both. The experiments do so by dissociating the likelihood that a verb is followed by a direct object from the likelihood that it is followed by an embedded subject. Note that "that" mention should vary with the likelihood that a verb is followed specifically by a direct object only if production is sensitive to the potential disruptiveness of a garden path, because it is the speaker's comprehender who will be sensitive to the fact that a noun phrase after a verb is likely to be a direct object. In contrast, if production is sensitive only to difficulty of production, then the likelihood that a verb is followed by a direct object -- a structure that the speaker does not intend to produce -- is irrelevant. By dissociating the likelihoods of a direct object versus an embedded clause, Experiments $3 \mathrm{a}$ and $3 \mathrm{~b}$ can determine if production is sensitive to the likelihood of a direct object, which should be the case if production is sensitive to the potential disruptiveness of a garden path, or if it is sensitive only to the likelihood that a verb is followed by an embedded clause, which should be the case if production is sensitive only to difficulty of production.

All experiments also included a manipulation of the plausibility of the embedded subject argument as a direct object (following Garnsey, et al., 1997). For example, "The proud mother announced (that) the wedding..." includes an embedded subject that is plausible as a direct object, whereas "The proud mother announced (that) the flowers..." includes an embedded subject that is implausible as a direct object. Garnsey et al. found that readers generally showed larger garden path effects when the embedded subject was a plausible direct object in these sentences. The production experiments here however never showed 
any effect of (or interaction with) the plausibility manipulation, and so it is not discussed further (the comprehension experiment shows a plausibility effect, replicating Garnsey et al., 1997, so that effect is briefly reported).

\section{Experiment 1}

The materials for Experiment 1 were taken from Garnsey et al. (1997). Speakers produced sentence complement structures including three types of verbs: direct-object biased verbs (verbs that relatively frequently take direct objects), embedded-clause biased verbs (verbs that relatively frequently take embedded clauses), and equibiased verbs (verbs that take direct objects and embedded clauses at intermediate rates relative to the other two verb classes). They produced sentences in a memory-based sentence-production task. Speakers read a critical sentence and a filler sentence in (apparently) random order each for $5 \mathrm{sec}$ and were asked to remember them. They were then prompted to produce the sentences back one at a time in (apparently) random order, as cued by the main subject and verb from each sentence. Half of the critical sentences speakers originally read included the "that" and half did not (counterbalanced across the other factors). Speakers in tasks like these have imperfect memory for the "that," as sentences are recalled based largely on the gist of the originally read sentence and less based on the superficial form of the sentence (e.g., E. Bates, Masling, \& Kintsch, 1978; Lombardi \& Potter, 1992; Sachs, 1967). This allows other factors such as the bias of the main verb to influence speakers' "that" mention (see V. S. Ferreira, 2003; V. S. Ferreira \& Dell, 2000; V. S. Ferreira \& Firato, 2002; Lee \& Gibbons, 2007). If the pattern found by Garnsey et al. (1997) with written sentence completion, as well as what has been revealed using corpus based evidence (Jaeger, 2010) happens also in online spoken production, then speakers should say the "that" most in sentences with directobject biased verbs, least in sentences with embedded-clause biased verbs, and equibiased verbs should be in between.

Method

Subjects-Forty-eight members of the UCSD community participated in Experiment 1. They received either course credit or cash payment. All reported learning English as their first language.

Apparatus-Speakers were tested on Macintosh computers using PsyScope (Cohen, MacWhinney, Flatt, \& Provost, 1993). Head-worn microphones were connected to standard audio cassette recorders and a PsyScope serial button box to record speakers' utterances and to detect voice onsets.

Procedure-Speakers pressed the space bar to begin each trial. After a $1 \mathrm{sec}$ blank interval, speakers saw the first sentence to be remembered (all stimuli were centred vertically and horizontally on the screen), which remained on the screen for $5 \mathrm{sec}$. Speakers were asked to read the sentence aloud, to ensure accurate encoding. After another $1 \mathrm{sec}$ blank interval, speakers saw the second sentence to be remembered, also for $5 \mathrm{sec}$. After a 1 sec blank interval, speakers were shown the main subject and verb of one of the just presented sentences, and were asked to say back the complete original sentence. They were given 4 sec to produce back the sentence (as triggered by a voice key), at which point a beep 
sounded. Speakers were encouraged to attempt to recall the sentence before beginning to speak, to reduce disfluency. The other sentence was then prompted similarly.

The order that sentences were presented for encoding and recall was pseudo-randomly determined. From the speakers' perspective, the sentences can be prompted in the same or in the opposite order as presented; half of all critical trials were presented in each of these orders, so that speakers would not be biased to anticipate the recall of the first- or secondpresented sentence (thus requiring speakers to remember both sentences). However, to reduce the likelihood that speakers would remember the critical sentence verbatim, the order where the critical sentence was presented second and then immediately prompted for recall was never used, and was replaced with the order where the critical sentence was presented first and then prompted second. This means that on half of trials, the encoding and recall of the critical sentence was separated by both the encoding and the recall of the filler sentences, whereas on the other half of trials, the encoding and recall of the critical sentence was separated by either the encoding or the recall of the filler sentence.

The experimental session began with a brief procedure to calibrate the voice key. Speakers were then given the instructions for the experiment, including a step-by-step presentation of the procedure using a sample sentence. Speakers were then presented with five practice trials that were the same in form as the critical trials.

Materials, design, and analysis-The critical sentences were taken from Garnsey et al. (1997). These were 48 pairs of sentence-complement structures consisting of a main subject, a main verb, an optional "that," an embedded subject, and then the rest of the embedded clause. The main subject was always three words long and typically was a determiner, an adjective, and a noun. The main verb was either direct-object biased, equibiased, or embedded-clause biased, with 16 pairs of sentences of each bias. Each sentence had a different main verb. In one sentence of each pair, the embedded subject was a potentially plausible direct object, whereas in the other sentence of the pair, it was implausible (as noted above, this manipulation was ineffective and so is not formally reported). The remainder of the embedded clauses continued to complete multiple-word verb phrases. Examples of sentences including verbs of each verb bias are shown in Table 1, along with the percentages of sentences of each verb type that were completed as one of the two critical sentence types (from normative data collected by Garnsey, et al., 1997).

One factor of interest was manipulated: Verb bias, referring to whether the sentencecomplement structures speakers produced included main verbs that were direct-object biased, equibiased, or embedded clause biased. This factor was manipulated within speakers and between items. The sentences were manipulated also according to two additional factors: The embedded subject of the sentence was either a plausible or an implausible direct object, and the optional "that" was included or omitted in the sentence speakers encoded. All factors were manipulated in counterbalanced fashion, such that each speaker saw each verb once, and saw equal numbers of sentences with plausible and implausible embedded subjects, and with and without the "that"; every verb was presented in a sentence with plausible and implausible embedded subjects, and with and without the "that" across subjects. 
The proportion of sentences speakers produced with the "that" was calculated for each speaker across sentences (in the speaker analysis) and for each sentence across speakers (in the items analysis) within each condition. (Percentages are reported for readability.) These proportions were entered into two $3 \times 2$ analyses of variance (ANOVAs) with the factors verb bias (direct-object biased, equibiased, embedded clause biased) and "that" inclusion ("that" included or omitted in the originally presented sentence). ANOVAs across speakers $(F 1)$ and items (F2) are presented. All analyses were also conducted on arcsine-transformed proportions; all significant effects were also significant after the arcsine transformation. Variation is reported with 95\% confidence interval halfwidths (CIs) based on single degreeof-freedom comparisons as calculated from ANOVA output (Loftus \& Masson, 1994; Masson \& Loftus, 2003). Significant effects achieved the .05 level or better.

In addition to ANOVAs on aggregate proportion data, we analysed the data using logistic regressions (linear mixed effects models with a logit link) on the individual trial-level data (Jaeger, 2008). In order to fit the models, the lmer function from the lme4 package (D. Bates, Maechler, \& Dai, 2009) was used within the R Environment for Statistical Computing (R Development Core Team, 2011). For Experiment 1, the models included verb bias, defined as a continuous variable, and whether the sentence was presented with a "that" as fixed effects and subjects and items as crossed random effects (Baayen, Davidson, \& Bates, 2008). Continuous verb-bias values were taken from norms collected by Garnsey et al., 1997, and were defined as the proportion of sentences for a particular verb that completed with embedded clause continuations divided by the sum of the proportions for that verb completed as embedded clause continuations plus direct object continuations. The random effects structure included random intercepts and random slopes of verb bias and "that"-presentation for subjects and random intercepts and random slopes of "that"presentation for items (because verb bias is a between-items variable). Both "that"presentation and verb bias were centred to allow for the interpretation of the main effects at the average value of the other factor (i.e., regardless of "that"-presentation and at the average value of verb bias). Because the dependent measure is a binary outcome (i.e., whether the subject mentioned "that" or did not), we used a generalized linear mixed model with a logit link, for which the test statistic is a $\mathrm{z}$-value. The $\mathrm{b}$ values are estimates of effect size in logit space so they cannot be directly interpreted.

\section{Results}

Speakers produced 2,304 critical sentences. Sentences were excluded from analysis if (a) the originally presented sentence was not read aloud accurately (169 sentences); (b) the speaker did not recall a sentence-complement structure (558 of the remaining sentences); (c) the speaker did not produce the correct main verb (19 of the remaining sentences). In total, $1,558(67.6 \%)$ of sentences remained for analysis. Table 2 shows the percentages of exclusions per condition.

The percentages of "that" speakers produced in sentence-complement structures with directobject biased, equibiased, and embedded clause biased verbs are shown in Figure 1. These percentages are reported separately in Table 2 separately for whether a "that" was in the original sentence. Speakers produced the "that" most in sentence-complement structures 
with direct-object-biased verbs ( $80.8 \%$ of sentences), least in sentence-complement structures with embedded clause biased verbs (66.1\% of sentences), with equibiased verbs falling between these (73.6\% of sentences). This led to a significant main effect of verb bias, $F 1(2,94)=15.1, \mathrm{CI}= \pm 5.3 \%, F 2(2,45)=7.98, \mathrm{CI}= \pm 7.2 \%$. The main effect of whether the original sentence included the "that" was also significant, $F 1(1,47)=46.9, \mathrm{CI}= \pm 5.6 \%$, $F 2(1,45)=51.4, \mathrm{CI}= \pm 5.3 \%$. This shows that speakers said the "that" more when the original sentence included the "that" than when the original sentence omitted it. The interaction between these factors was nonsignificant, $F 1(2,94)=1.05, \mathrm{CI}= \pm 7.6 \%, F 2(2$, $45)=1.39, \mathrm{CI}= \pm 9.1 \%$.

Mixed effects analyses revealed similar results to the ANOVAs: There was a significant effect of verb bias, $\mathrm{b}=-1.57, \mathrm{SE}=.40, \mathrm{z}=-3.93, p<.005$, with speakers saying "that" less as the likelihood that the verb implied an embedded clause structure increases. Whether the probe sentence included a "that" also significantly increased the likelihood that subjects would produce a "that", $\mathrm{b}=1.54, \mathrm{SE}=.19, \mathrm{z}=8.05, p<.001$, and there was no interaction, such that the effect was not significantly different across different degrees of verb bias ( $p$ $>$.26).

\section{Discussion}

The results of Experiment 1 confirm that verb bias systematically affects "that" mention: Speakers produced the optional "that" more in sentence-complement structures with main verbs that are often produced with direct objects than in sentence-complement structures with main verbs that are often produced with embedded clauses; sentence-complement structures with main verbs that were intermediate in this bias were produced with "that" at an intermediate rate. This replicates and extends observations with written and corpus methods, and is consistent with both accounts outlined in the introduction: Speakers may say the "that" more in sentence-complement structures with main verbs that usually take direct objects, because comprehenders find garden paths in sentences with such verbs more disruptive; or speakers may say the "that" more in sentence-complement structures with main verbs that rarely take embedded clauses because they find producing such structures with those verbs to be relatively more difficult, and speakers say "that" in more difficult-toproduce sentences.

One concern with Experiment 1 comes from the memory-based sentence-production task that was used. Specifically, in this task, speakers must read the entire sentence-complement structure before producing it. Presumably, as in the Garnsey et al. (1997) study, speakers will experience a more disruptive garden path when reading ("that"-less) sentence complement structures with direct-object biased main verbs than when reading ("that"-less) sentence-complement structures with embedded clause biased verbs. This raises the possibility that it was the disruption that speakers themselves experienced when reading the sentence that influenced "that" mention rather than the bias of the verb. Experiment 2 addressed this concern. 


\section{Experiment 2}

Experiment 2 was a replication of Experiment 1 with two main differences. First, instead of a memory-based sentence-production task, speakers in Experiment 2 were tested with a sentence-combination task. Here, speakers are given two relatively simple sentences, and are asked to combine them into one longer sentence. As such, speakers never read complete sentence-complement structures in Experiment 2, and so would not experience any garden paths before producing critical sentences. If the result in Experiment 1 happened because speakers read sentences before producing them, then the effect of verb bias should not be observed in Experiment 2. Second, speakers produced different sentences (provided by Susan Garnsey, personal communication, July 12th, 2002). The equibiased condition was eliminated, and additional sentences were added to the direct-object biased and embedded clause biased conditions.

\section{Method}

Subjects-Fifty-one speakers from the same population as Experiment 1 participated in Experiment 2. Data from four speakers were removed from analyses because recording difficulties caused nearly all of their productions to be lost, and data from two more speakers were eliminated because exclusions (described below) eliminated more than $75 \%$ of their critical productions. (All subjects tested in Experiments 1 and 3 exceeded this criterion.)

Apparatus-Apparatus was as in Experiment 1.

Procedure-At the beginning of each trial, speakers were shown the current trial number and pressed the space bar to proceed. After a $500 \mathrm{~ms}$ blank interval, speakers saw a fixation point for $1 \mathrm{sec}$ (all stimuli were centred vertically and horizontally). Two sentences were then presented consecutively, each for $3 \mathrm{sec}$ after a $500 \mathrm{~ms}$ blank interval. After another 500 ms blank interval, a prompt to combine the two sentences (" $\rangle\langle$ ") was shown. The prompt remained on the screen until the voice key detected the speaker's production.

Speakers were given a cover story that they were a story writer for a high-level newspaper which tended to publish stories with longer and more complicated sentences. They were thus to practice taking simple sentences and combining them into more complex ones. Speakers were specifically instructed not to change the meaning that the two sentences expressed.

The session began with instructions and practice, as in Experiment 1. There were 12 trials in the practice session.

Materials, design, and analysis-Eighty pairs of critical sentence-complement structures were developed. These came from 40 different verbs, such that every verb was used in two pairs of sentences. The constitution of the sentence-complement structures was as in Experiment 1. The pairs implemented a plausibility manipulation, as in Experiment 1. Each (critical and filler) sentence was broken into two simpler sentences. For the sentencecomplement structures, these were one sentence including the main subject, main verb, and "something" (e.g., "The talented photographer accepted something.") and another including the rest of the sentence (e.g., "The money could not be spent yet."). Sixty-eight filler 
sentences were added to each list, so that speakers produced a total of 148 sentences. Fillers were designed to elicit sentences of different types (other than sentence complement structures), including simple sentences, relative clause structures, and so forth. Table 3 shows an example of sentence-complement structures with each main-verb bias.

The experiment included one primary factor of interest: The main verb in the sentencecomplement structure was either direct-object biased or embedded clause biased. This factor was manipulated within subjects and between items. One other factor, the plausibility of the embedded subject as a direct object, was crossed with verb bias and was within-subjects and items. Statistical analyses were conducted as in Experiment 1, except dropping the factor assessing whether the "that" was originally presented.

Mixed effects analyses for Experiment 2 were similar to Experiment 1 with the following exceptions. The only fixed effect was verb bias, which included only direct object biased verbs and embedded clause biased verbs. Only random intercepts were used for items, since verb bias is a between-items factor. Random intercepts and random slopes of verb bias were included for subjects.

\section{Results}

A total of 3,600 productions were eligible for analysis. Trials were eliminated if (a) the speaker did not produce a sentence-complement structure (476 trials) or (b) the speaker produced the wrong main verb (482 remaining trials). In total, 2,642 (73.4\%) of sentences remained to be analysed. Table 3 reports percentages of excluded trials per condition.

Figure 2 shows the percentages of "that" speakers produced in sentence-complement structures with direct-object biased and embedded clause biased main verbs. Speakers produced the "that" about 7.2\% more in sentence complement structures with direct-object biased main verbs (70.5\% of sentences) than in sentence-complement structures with embedded-clause biased main verbs (63.3\% of sentences). This difference was significant, $F 1(1,44)=16.2, \mathrm{CI}= \pm 3.6 \%, F 2(1,78)=11.4, \mathrm{CI}= \pm 4.6 \%$. Mixed effects analyses revealed a significant effect of verb bias, $\mathrm{b}=-.97, \mathrm{SE}=.33, \mathrm{z}=-2.98, p<.005$, with fewer "that"s being included as the likelihood of the verb taking an embedded clause increases.

\section{Discussion}

Experiment 2 replicates Experiment 1: Speakers produced the "that" more in sentencecomplement structures with main verbs that are direct-object biased than in sentencecomplement structures with main verbs that are embedded-clause biased. Thus, the pattern observed in these online production tasks is not because of any effect of comprehending a full sentence-complement structure before producing one, because speakers in Experiment 2 did not read full sentence-complement structures before producing them.

Experiments 1 and 2 demonstrate that speakers' mention of the "that" in a sentencecomplement structure is sensitive either to how often the main verb in the sentencecomplement structure occurs with direct objects, or to how often the main verb in the sentence-complement structure occurs with embedded clauses, or both. The first of these (degree of direct-object bias) should influence "that" mention only if speakers are sensitive 
to the degree of potential disruptiveness of the garden path in a sentence-complement structure. In contrast, only the second of these (degree of embedded clause bias) should influence "that" mention if speakers find it more difficult to produce sentence-complement structures with verbs that are not produced in such structures relatively often. But because the verb classes in Experiments 1 and 2 (inversely) confounded the degree of direct-object bias and the degree of embedded clause bias, Experiments 1 and 2 are unable to distinguish these alternatives.

In Experiment 3, a third class of verb is introduced that unconfounds the two biases: neitherbiased verbs. These are verbs like "agree" that rarely take direct objects or embedded clause arguments, because they instead often take other sorts of arguments (like prepositional phrases, infinitival clauses, and so forth). In particular, here, neither-biased verbs took direct objects about $15 \%$ of the time and embedded clauses about $15 \%$ of the time (see Table 4 below). Consider first the possibility that speakers are sensitive to how disruptive their produced garden paths might be. Upon hearing a neither-biased verb, a comprehender might immediately estimate that the likelihood of a direct object is low (15\%); if so, then the garden path they experience will be mild. This is the same likelihood that an embedded clause biased verb here has of taking a direct object (15\%), and a much lower probability than a direct object biased verb has of taking a direct object (73\%; see Table 4). Thus, if speakers say the "that" to avoid especially disruptive garden paths, then they should say the "that" equally rarely in sentences that have neither- and embedded clause biased verbs, and they should say "that" much more in sentences that have direct-object biased verbs. A more sophisticated comprehension-sensitive account is that upon comprehending a neither-biased verb followed by a noun phrase, a comprehender might estimate the likelihood that the noun phrase is a direct object at about $50 \%$. This would be because, although the likelihood of a direct object overall is just $15 \%$, the comprehender will encounter the noun phrase before the potential garden path, and so may be able to discard from consideration any outcome that is not a noun phrase even before being garden pathed. This leaves direct objects and embedded clauses, each having a 15\% overall likelihood, meaning that each has a 50\% likelihood relative to the other $(15 \% /(15 \%+15 \%))$. This $50 \%$ likelihood of a direct object with neither biased verbs compares to an analogous $16 \%$ likelihood of a direct object with embedded clause biased verbs $(14 \% /(14 \%+72 \%))$, and an $83 \%$ likelihood for directobject biased verbs $(73 \% /(73 \%+15 \%))$. Therefore, on this more sophisticated comprehension-sensitive account, speakers should say the "that" most in sentences with direct-object biased verbs ( $83 \%$ chance of a direct object), at intermediate rates in sentences with neither biased verbs (50\% chance of a direct object), and least with embedded clause biased verbs ( $16 \%$ chance of a direct object).

Meanwhile, if speakers are sensitive to how difficult a sentence is to produce, and if it is harder to produce sentence complement structures as a function of how often the verbs in those structures are produced with embedded clauses, then only the likelihood (or, frequency, as far as production is concerned) of a verb taking an embedded clause is relevant. Embedded clause biased verbs are produced with embedded clauses about $73 \%$ of the time (see Table 4), whereas direct-object biased and neither-biased verbs are produced with embedded clauses just $15 \%$ of the time. If the mention of "that" is sensitive just to production difficulty as reflected by frequency, speakers should say the "that" less in 
sentences with embedded clause biased verbs than in sentences with neither- and directobject biased verbs, which in turn should be produced with the "that" about equally.

The predictions of the two comprehension-sensitive and the production sensitive accounts are shown in Figure 3. According to all accounts, speakers should say the "that" more in sentences with direct-object biased verbs than in sentences with embedded clause biased verbs, as observed in Experiments 1 and 2. Critical are neither-biased verbs. On either comprehension-sensitive account, speakers should say the "that" less in sentences with neither-biased verbs than in sentences with direct-object biased verbs. The productionsensitive account, in contrast, predicts that speakers should say the "that" in sentences with neither-biased verbs and in sentences with direct-object biased verbs about equally.

(Note that these predictions regarding neither-biased verbs differ from predictions regarding the equibiased verbs from Experiment 1. Critical is that the equibiased verbs in Experiment 1 take embedded clauses at intermediate rates (36\%), whereas neither-biased verbs in Experiment 3 take embedded clauses at low rates (15\%). As a result, whether speakers mention the "that" to avoid disruptive garden paths or as a result of producing a more difficult to produce sentence, speakers should say the "that" at intermediate rates with equibiased verbs in Experiment 1. Put somewhat differently, in Experiment 1, the three verb types inversely confounded the likelihood that verbs take direct objects versus embedded clauses; in Experiment 3, the neither-biased verbs break this confound.)

Experiment 3 consists of two sub-experiments (Experiments $3 \mathrm{a}$ and $3 \mathrm{~b}$ ). Experiment $3 \mathrm{a}$ tests production, to see how often speakers say the "that" in sentence complement structures with neither-biased verbs, as compared to sentence-complement structures with direct-object or embedded clause biased verbs. Note however that previous work has not investigated the comprehension of sentence-complement structures with neither-biased verbs, so Experiment $3 \mathrm{~b}$ assessed whether comprehenders indeed take noun phrases after neither-biased verbs to be direct objects less than noun phrases after direct-object biased verbs.

\section{Experiment 3a}

\section{Method}

Subjects-Seventy-two speakers from the same population as Experiment 1 participated in Experiment 3a.

Procedure-The procedure was identical to that in Experiment 2.

Materials, design, and analysis-Forty-two new pairs of sentence-complement structures were constructed. The main subjects of these were single proper names. The main verb was either direct-object biased, embedded clause biased, or neither-biased. The embedded subject was a simple noun phrase that was manipulated for plausibility. The rest of the embedded clause included at least two more words. Table 4 shows an example of sentence-complement structures with main verbs of each bias. Forty-two filler sentences that were designed to elicit a variety of structures (other than sentence-complement structures) were added to each list. 
The design and analyses were as in Experiment 1, but with neither-biased verbs instead of equibiased verbs, and without any manipulation of whether the original sentence included a "that" (because the sentence-combination paradigm does not require sentences to include or omit the "that"). Mixed effects analyses were similar to Experiment 2 with the addition of the neither-biased verbs as a level of verb bias.

\section{Results}

A total of 3,024 productions were eligible for analysis. Trials were excluded if (a) subjects did not produce a sentence-complement structure (538 trials), or (b) the sentence was produced with the wrong main verb (57 remaining trials). In all, 2,429 trials (80.3\%) remained for analysis. Percentages of excluded trials per condition are shown in Table 4 .

Figure 3 shows the percentages of "that" produced in sentence-complement structures with direct-object biased, neither-biased, and embedded-clause biased main verbs. As in Experiments 1 and 2, speakers produced the "that" more in sentence-complement structures that had direct-object-biased main verbs $(71.2 \%)$ than in sentence-complement structures that had embedded-clause biased verbs (63.1\%). Importantly, speakers did not produce the "that" in sentence-complement structures with neither-biased main verbs statistically less than in sentence-complement structures with direct-object biased main verbs, as speakers produced the "that" in $69.1 \%$ of sentence-complement structures with neither-biased verbs. The main effect of verb bias was significant by subjects, $F 1(2,142)=9.21, \mathrm{CI}= \pm 3.9 \%$, though not by items, $F 2(2,39)=1.57, \mathrm{CI}= \pm 9.5 \%$; the items analyses has substantially less statistical power both because verb type is manipulated between items, and because only 14 items per condition could be found, given limitations on the number of verbs that are neither biased. Note that given the by-subjects confidence interval of 3.9\%, the $2.1 \%$ difference found between sentences with direct-object biased verbs versus with neither-biased verbs is nonsignificant. Meanwhile, the $8.1 \%$ difference between sentences with direct-object versus embedded clause biased verbs was significant, as was the $6.0 \%$ difference between sentences with neither-biased versus embedded clause biased verbs. This is most consistent with the pattern shown in Figure 3c, the one predicted if verb bias effects reflect difficulty of production. The small number of items also compromised power in the mixed effects analyses, as there was no significant difference between the direct object biased verbs and either the neither biased or the embedded clause biased verbs ( $p>.68)$.

\section{Discussion}

Speakers produced the "that" in sentence-complement structures with verbs biased neither toward direct-objects nor toward embedded clauses relatively often -- statistically as often as they produced the "that" in sentence-complement structures with verbs biased toward direct objects, and significantly more often than they produced the "that" in sentence-complement structures with verbs biased toward embedded clauses. Because the noun phrases after neither-biased verbs are less likely to be direct objects, the observation that speakers did not say the "that" in sentence-complement structures with neither-biased verbs less than they did in sentence-complement structures with direct-object biased verbs suggests that it is not a sensitivity to the disruptiveness of a garden path that drives speakers' mention of the "that." Rather, neither-biased and direct-object biased verbs are similar in that that both types of 
verbs are rarely produced with embedded clauses, and this is likely what drives the higher "that" mention in both cases.

\section{Experiment 3b}

The logic of Experiment 3a relies on the claim that the difficulty induced by a garden path is driven at least in part by how likely a noun phrase after a verb is to be a direct object -- the less so, the less disruptive the interference should be when the direct-object analysis proves incorrect. If not -- if comprehension processes suffer equal garden-path effects regardless of how often a main verb takes a direct object argument (say, because garden paths are sensitive only to how often a main verb takes a sentence complement) -- then direct-object biased verbs and neither-biased verbs should be equally disruptive. If direct-object biased verbs and neither-biased verbs are equally disruptive, then on a comprehension-sensitive account (as on a production-sensitive account), speakers should say the "that" about equally in sentences with the two types of verbs, as was observed in Experiment 3a.

Experiment $3 \mathrm{~b}$ assessed whether the post-verbal noun phrases in sentence-complement structures with neither-biased main verbs are less likely to be taken as a direct object than post-verbal noun phrases in sentence-complement structures with direct-object biased main verbs. If so, then it is likely that sentence-complement structures with neither-biased verbs cause less disruptive garden paths. To do so, the experiment used a sentence-completion task to assess the comprehension biases of the to-be-produced sentence-complement structures when they had direct-object biased, embedded clause biased, and neither-biased main verbs. For critical sentences, subjects were presented with the main subject, main verb, and embedded subject of the sentence-complement structure speakers produced in Experiment 3a (e.g., "Jenny anticipated the turn..."), and were asked to complete the sentence as they wished. To do so, subjects had to read and understand the main subject, main verb, and post verbal noun phrase. This requires that the subject interpret the post-verbal noun phrase as an embedded subject, a direct object, or some other type of argument. The subjects' completion was then analysed to determine how they interpreted the post-verbal noun phrase. We expected subjects to interpret post-verbal noun phrases after embedded subject biased main verbs to be embedded subjects more than post-verbal noun phrases after direct-object biased verbs, implying that subjects would suffer less of a garden path with embedded subject biased verbs. Of particular interest is whether subjects interpreted the post-verbal noun phrases after neither-biased verbs as direct objects less than the post-verbal noun phrases after direct-object biased verbs, which on a comprehension-sensitive account of "that"mention predicts that speakers should say the "that" less in sentence-complement structures with neither-biased verbs.

It is worth noting that this task is not a direct assessment of the comprehension of garden path sentences. We did design and execute an eye-tracking experiment to assess the disruptiveness of the sentences in Experiment 3a directly. Results showed no differences among any conditions at all, including between sentences with direct-object and embedded clause biased verbs, failing to replicate Garnsey et al. (1997). We assume that because the sentences in Experiment 3a were not designed for an eye tracking study, their properties rendered them a poor fit for proper assessment using eye tracking. As such, we elected to 
use the simpler sentence-completion methodology used here, so that we could assess the exact sentences used in Experiment 3a, even if the measure only indirectly indexes the likelihood that a comprehender will interpret the post-verbal noun as the direct object, thereby leading to a garden path.

\section{Method}

Subjects-Twenty-six subjects from the same population as Experiment 1 participated in Experiment $3 b$.

Procedure-Subjects completed a web-based form. For each stimulus, subjects were presented with the written beginning of a sentence on one line. The next line was a blank slot. Subjects were instructed to complete each sentence by entering text into the blank slot with a completion that used as many words as they wished, but that must include at least one word. Subjects completed the form at their own pace.

Materials, design, and analysis-Experiment $3 b$ tested truncated forms of the sentences constructed for Experiment 3a. All critical sentences were truncated after the embedded subject noun phrase. Half of the sentences included the "that," and half did not, counterbalanced across subjects and items. Across all eligible trials, 97.8\% sentences with "that" were completed as sentence-complement structures, so trials with the "that" are not considered further. Filler sentences were truncated at a point after the main verb but before the end of the sentence. Note that the post-verbal noun phrases in Experiment 3a were manipulated for plausibility, and so for comparability, the post-verbal noun phrases in Experiment $3 \mathrm{~b}$ were manipulated for plausibility as well. Because this manipulation had a strong effect on the sentence-completion results, these are analysed further below.

A research assistant naive to the experimental hypotheses coded all sentence completions for whether the post-verbal noun phrase was interpreted as a direct object, an embedded subject, or some other argument. The main dependent variable is the proportion of trials where subjects took the post-verbal noun phrase as a direct-object argument. Sentences were manipulated for whether the main verb was embedded clause biased, direct-object biased or neither biased, as well as for the plausibility of the post-verbal noun phrase as a direct-object noun phrase. Two items were excluded from the items analyses because of empty cells.

Mixed effects models in Experiment 3b were similar to Experiment 3a, with the inclusion of plausibility of the post-verb noun (centred) as a direct object as a fixed effect and random slopes for subjects and items. Instead of "that"-inclusion as the dependent variable, the dependent variable was whether the subject completed the sentence with a direct-object interpretation.

\section{Results}

A total of 546 sentence completions were eligible for analysis. Of these, 20 were excluded because subjects completed sentences with non-sensical completions, leaving 526 trials (96.3\%) for analysis. Percentages of excluded trials in each condition are shown in Table 4. 
Figure 4 shows the percentages of post-verbal noun phrases interpreted as direct-object noun phrases as a function of the bias of the main verb and the plausibility of the post-verbal noun phrase as a direct object. Post-verbal noun phrases after direct-object biased main verbs were $16.9 \%$ more likely to be interpreted as direct objects (63.5\%) than post-verbal noun phrases after neither-biased verbs $(46.6 \%)$. At the same time, post-verbal noun phrases after direct-object biased main verbs were $42.8 \%$ more likely to be interpreted as direct objects than post-verbal noun phrases after embedded clause biased verbs $(20.7 \%)$. These differences led to a significant effect of verb bias, $F 1(2,50)=36.6, \mathrm{CI}= \pm 10.1 \%, F 2(2,37)$ $=9.6, \mathrm{CI}= \pm 19.6 \%$. Most important is the observation that subjects took the post-verbal noun phrases after neither-biased verbs to be direct objects $16.9 \%$ less than the post-verbal noun phrases after direct-object biased verbs, which (given the $10.1 \%$ confidence interval on the main effect of verb type) is a significant difference (however, due to the small number of items and the resultant greater variability, this difference was marginally significant by items, $p<.07)$.

Post-verbal noun-phrases that were plausible direct objects were $34.6 \%$ more likely to be interpreted as direct objects than post-verbal noun phrases that were implausible direct objects $(60.9 \%$ vs. $26.3 \%)$, a significant difference, $F 1(1,25)=121, \mathrm{CI}= \pm 6.5 \%, F 2(1,37)$ $=40.1, \mathrm{CI}= \pm 10.7 \%$. Plausibility and verb type interacted by subjects only, $F 1(2,50)=$ $7.81, \mathrm{CI}= \pm 9.8 \%, F 2(2,37)=1.99, \mathrm{CI}= \pm 18.6 \%$, reflecting the observation that the plausibility difference was smaller for embedded-clause biased verbs (18.9\%) than for the direct-object biased (43.7\%) or neither-biased (41.3\%) verbs. As this interaction is not pertinent to the primary issues investigated in this paper, it is not discussed further.

Mixed effects analyses revealed a significant effect of verb bias, $\mathrm{b}=-6.46, \mathrm{SE}=.87, \mathrm{z}=$ $-7.39, p<.001$, with fewer sentences being completed with direct object interpretations as the likelihood of the verb taking an embedded clause structure increases. There was a significant effect of plausibility, $\mathrm{b}=3.10, \mathrm{SE}=.49, \mathrm{z}=6.33, p<.001$, such that sentence fragments with nouns that were more plausible as direct objects were more likely to be completed with direct-object interpretations. There was a significant interaction between plausibility of the noun and verb bias, $\mathrm{b}=-3.21, \mathrm{SE}=1.52, \mathrm{z}=-2.11, p<.05$, with the effect of plausibility being smaller as the likelihood for the verb to take an embedded clause increases.

\section{Discussion}

Experiment 3a revealed that speakers did not consistently mention the "that" in sentencecomplement structures with neither-biased verbs less than in sentence-complement structures with direct-object biased verbs. That is, speakers treated sentence-complement structures with neither- and direct-object biased verbs the same, even though comprehenders ought to take any immediate post-verbal noun phrase as less likely to be a direct object after neither-biased verbs than after direct-object biased verbs. Experiment $3 \mathrm{~b}$ confirmed this latter observation, showing that when comprehenders were presented with noun phrases immediately after neither-biased verbs, they interpreted them as direct objects less than noun phrases after direct-object biased verbs. This suggests that sentences with neither-biased verbs likely cause weaker garden paths, though direct demonstration of this effect with 
sentences designed for comprehension study would strengthen this conclusion. (It is reassuring, however, that plausibility affected the likelihood that subjects took post-verbal noun phrases as direct objects, which is analogous to the garden path effects reported in Garnsey et al., 1997.) At the same time, speakers did mention the "that" in sentencecomplement structures with embedded clause biased verbs less than in sentence-complement structures with direct-object (or neither-) biased verbs. Together, these observations suggest that speakers mention the "that" in sentence-complement structures at different rates as a function of the bias of the main verb not because of any estimate of how difficult the sentence will be for their comprehenders (in terms of a garden-path effect), but rather because of how difficult it is to produce that sentence structure continuation given that verb. Verbs that are more frequently produced in sentence complement structures are presumably produced more easily in such structures, and so speakers mention the "that" in them less; verbs that are less frequently produced in sentence complement structures are presumably produced with more difficulty in such structures, and so speakers mention the "that" in them more.

\section{General Discussion}

Two main points follow from the current experiments:

1. Speakers say the "that" more in sentence-complement structures with direct-object biased verbs than in sentence-complement structures with embedded-clause biased verbs. This confirms offline results reported in Garnsey et al. (1997) and corpus results reported by Jaeger (2010).

2. But the mention of the "that" is not sensitive to how often the main verb in a sentence-complement structure appears with a direct object. Neither-biased verbs -verbs that do not often appear with direct objects -- nonetheless are produced in sentence-complement structures relatively often with the "that." Rather, what seems to influence "that" mention is how rarely speakers produce sentences with particular verbs as sentence-complement structures; the less a main verb tends to appear with an embedded clause, the more likely speakers are to say the "that."

\section{Implications for how speakers communicate successfully}

The observation that speakers do not avoid producing garden paths more in sentences where that garden path would be more disruptive (in those with direct-object biased verbs) fits with other results in the literature. V. S. Ferreira and Dell (2000) reported that speakers do not say the "that" more in recalled sentence-complement structures with embedded subjects that could be interpreted as direct objects (and so permitted garden path interpretations) compared to in sentences with embedded subjects that could only be interpreted as embedded subjects (and so did not permit a garden-path interpretation; e.g., "The coach knew (that) you..." vs. "The coach knew (that) I...”). V. S. Ferreira (2006) reported a similar result, but in written production, and when writers were given specific instructions to write sentences that were as easy to understand as possible. V. S. Ferreira and Hudson (2011) also showed a similar effect, but in relatively naturalistic interactive dialogue. Arnold, Wasow, Asudeh, and Alrenga (2004) showed that speakers don't avoid garden paths in a different 
structure, namely, a prepositional dative (e.g., "The foundation gave Grant's letters to Lincoln to a museum in Philadelphia”). Kraljic and Brennan (2005) showed that speakers do not disambiguate garden path sentences with prosody any more in ambiguous situations than in unambiguous situations. And Snedeker and Trueswell (2003) showed that only speakers who were consciously aware of a potential garden path used prosody to avoid that garden path more in ambiguous situations than in unambiguous situations. Two results suggest speakers do avoid garden paths: Temperley (2003) and Haywood, Pickering, and Branigan (2005). It may be that other confounding factors were responsible for the effects in these experiments, or that the effects may not be especially robust (Roland, Dick, \& Elman, 2007). It also may be that especially long (and so potentially disruptive) ambiguities are at least weakly avoided (Jaeger, 2010). At the very least, the bulk of evidence suggests that speakers do not generally avoid garden path sentences.

The current evidence goes beyond previous results in one important way, however. In previous demonstrations, the difference between the garden-path and non-garden path situations hinged on features of the specific sentences speakers produced or the specific context in which the production was situated. For example, to say the "that" more in sentence-complement structures beginning "The coach knew (that) you..." versus "The coach knew (that) I...," speakers must recognise that a particular noun phrase ("you") is ambiguous in just the way that allows a garden path in the to-be-produced sentencecomplement structure, and that another pronoun ("I") is not. This requires that speakers determine online as they produce the sentence that it may or may not include a garden path. Here, no such online determination was necessary. In principle, speakers could build into their "offline" lexicalized grammatical knowledge a bias to say the "that" more in sentencecomplement structures that are generally more disruptive -- those that are often followed by direct objects. Still, even a sensitivity to comprehension difficulty that speakers could represent in a (relatively) static across-the-board way does not seem to guide speaker behaviour.

These results fit with the idea that there is a division of labor for communicative success (V. S. Ferreira, 2008; see also Clark \& Wilkes-Gibbs, 1986, for the notion of minimal collaborative effort). By this account, speakers in general do not produce sentences that are designed to be as easy to understand as possible (for example, by avoiding garden paths) because to do so is beyond the speakers' responsibility. The time and effort speakers likely require to try to craft optimally comprehensible utterances may simply be too costly. Instead, speakers are responsible for producing utterances that will convey their meanings sufficiently -- even if they are not optimal for subsequent comprehension -- and to do so with some dispatch. If a speaker's addressee has some difficulty comprehending the sentence, communication will likely still succeed well enough (F. Ferreira \& Patson, 2007). If the addressee has excessive difficulty, she or he can interrupt the conversation, request clarification, and so forth. The current results extend this framework by showing that the relatively static biases speakers might have that guide sentence production also do not reflect comprehension sensitivity, at least as induced by garden-path sentences. By this view, overall, speakers and their production biases guide the production process; the subsequent comprehension process does not. 
It is worth noting that when considering whether speakers choose sentence features (e.g., the "that") to formulate easier-to-understand sentences, the current work (as well as much research in the literature) has focused on garden path-type effects. It may be that speakers' production behaviour might be sensitive to other factors that disrupt comprehension, especially if the disruptiveness could exceed that precipitated by garden paths (as just noted). Generalisation of the notion of a division of labor beyond ambiguity in general would be valuable.

\section{Non-retrieval-based influences on "that" mention}

One other novel implication follows from the current results. Previous demonstrations that speakers produce the "that" more in harder-to-produce sentences have largely examined factors that reflect how easy or hard it is to retrieve sentence content (e.g., whether words repeat or whether proactive interference is greater, as reviewed in the introduction here). The current results suggest that difficulty as measured by greater "that" mention can also come from speakers' past experience, in particular, how often they have produced particular structures with particular verbs. This is consistent with corpus studies on syntactic production in spontaneous speech (Jaeger, 2006, 2010; Levy \& Jaeger, 2007; Resnik, 1996), as well as analyses of /t/ and /d/ deletion and prosodic reduction (Gahl \& Garnsey, 2004). This shows that the production of sentence structure might be sensitive to frequency in the same way as, say, the production of individual words (Oldfield \& Wingfield, 1964). This fits well with approaches to production that view everyday language use as shaping speakers' knowledge of the features of their language (Chang, 2002; Chang, Dell, Bock, \& Griffin, 2000; Chang, Dell, \& Bock, 2006).

The current results -- including that neither-biased verbs were produced with "that" more -are also consistent with claims of how uniform information density influences language production (Jaeger, 2010). In terms of cognitive mechanism, greater frequency likely yields easier production. But in terms of mechanism-independent information, greater relative frequency of a syntactic structure corresponds to less informativeness from that syntactic structure. Indeed, the two accounts can be seen as different levels of description of the same sort of phenomenon. Uniform information density is a computational level explanation that characterises the design of certain classes of effects in sentence production. The effects of frequency observed here or retrievability in previous work can be seen as how cognitive mechanisms implement such a computational account.

\section{Conclusions}

In principle, speakers' sentence choices might reflect a goal of being more easily understood, or they might reflect the ease or difficulty they had formulating sentences. Past research suggests that speakers do not choose one structure over another because they can assess online that that structure would be easier for their addressee to understand. The current research takes this further, and shows that speakers do not choose one structure over another because they have encoded in their grammatical knowledge that the chosen structure tends to be easier for addressees. Instead, speakers have the responsibility of managing their own production burdens, so that they can say utterances efficiently. If their grammar offers 
some flexibility in the choice of an utterance on a particular occasion, they use that flexibility to promote that efficiency.

\section{Supplementary Material}

Refer to Web version on PubMed Central for supplementary material.

\section{Acknowledgments}

The research reported in this manuscript was supported by NIH R01 grant HD051030. Thanks to Katie Doyle, Carla Firato, Michelle Groisman, and Allison Peters for assistance with data collection and analysis, Susan Garnsey for her generosity with materials and advice, and Florian Jaeger and the members of the Language Production Laboratory at UCSD for discussion.

\section{References}

Arnold JE, Wasow T, Asudeh A, Alrenga P. Avoiding attachment ambiguities: The role of constituent ordering. Journal of Memory \& Language. 2004; 51:55-70.

Baayen RH, Davidson DJ, Bates DM. Mixed-effects modeling with crossed random effects for subjects and items. Journal of Memory and Language. 2008; 59:390-412.

Bates, D.; Maechler, M.; Dai, B. lme4: Linear mixed-effect models using S4 classes (R package Ver. 0.999375-28). Vienna, Austria: R Foundation for Statistical Computing; 2009.

Bates E, Masling M, Kintsch W. Recognition memory for aspects of dialogue. Journal of Experimental Psychology: Human Learning \& Memory. 1978; 4(3):187-197.

Bolinger, D. That's That. The Hague: Mouton; 1972.

Chang F. Symbolically speaking: A connectionist model of sentence production. Cognitive Science. 2002; 26:609-651.

Chang F, Dell GS, Bock JK, Griffin ZM. Structural priming as implicit learning: A comparison of models of sentence production. Journal of Psycholinguistic Research. 2000; 29(2):217-229. [PubMed: 10709186]

Chang F, Dell GS, Bock K. Becoming syntactic. Psychological Review. 2006; 113(2):234-272. [PubMed: 16637761]

Clark HH, Wilkes-Gibbs D. Referring as a collaborative process. Cognition. 1986; 22:1-39. [PubMed: 3709088]

Cohen JD, MacWhinney B, Flatt M, Provost J. PsyScope: An interactive graphic system for designing and controlling experiments in the psychology laboratory using Macintosh computers. Behavior Research Methods, Instruments, and Computers. 1993; 25:257-271.

Ferreira F. Choice of passive voice is affected by verb type and animacy. Journal of Memory and Language. 1994; 33:715-736.

Ferreira, F.; Engelhardt, PE. Syntax and production. In: Gernsbacher, MA.; Traxler, MJ., editors. Handbook of Psycholinguistics. Oxford, UK: Elsevier; 2006. p. 61-91.

Ferreira F, Henderson JM. Use of verb information in syntactic parsing: Evidence from eye movements and word-by-word self-paced reading. Journal of Experimental Psychology: Learning, Memory, and Cognition. 1990; 16:555-568.

Ferreira F, Patson N. The good enough approach to language comprehension. Language and Linguistics Compass. 2007; 1:71-83.

Ferreira VS. The persistence of optional complementizer production: Why saying "that" is not saying "that" at all. Journal of Memory and Language. 2003; 48(2):379-398.

Ferreira VS. Avoid ambiguity! (If you can). Center for Research in Language Technical Reports. 2006; 18:1-13.

Ferreira VS. Ambiguity, accessibility, and a division of labor for communicative success. Psychology of Learning and Motivation: Advances in Research and Theory. 2008; 49:209-246. 
Ferreira VS, Dell GS. Effect of ambiguity and lexical availability on syntactic and lexical production. Cognitive Psychology. 2000; 40(4):296-340. [PubMed: 10888342]

Ferreira VS, Firato CE. Proactive interference effects on sentence production. Psychonomic Bulletin \& Review. 2002; 9:795-800. [PubMed: 12613685]

Ferreira VS, Hudson M. Saying "that" in dialogue: The influence of accessibility and social factors on syntactic production. Language and Cognitive Processes. 2011; 26:1736-1762. [PubMed: 23087498]

Gahl S, Garnsey SM. Knowledge of grammar, knowledge of usage: Syntactic probabilities affect pronunciation variation. Language. 2004; 80:748-775.

Garnsey SM, Pearlmutter NJ, Myers E, Lotocky MA. The contributions of verb bias and plausibility to the comprehension of temporarily ambiguous sentences. Journal of Memory and Language. 1997; 37:58-93.

Godfrey J, Holliman E, McDaniel J. SWITCHBOARD: Telephone speech corpus for research and development. Proceedings of ICASSP-92. 1992; 1:517-520.

Gregory ML, Raymond WD, Bell A, Fosler-Lussier E, Jurafsky D. The effects of collocational strength and contextual predictability in lexical production. Chicago Linguistics Society (CLS-99). 1999:151-166.

Haywood SL, Pickering MJ, Branigan HP. Do speakers avoid ambiguity during dialogue? Psychological Science. 2005; 16:362-366. [PubMed: 15869694]

Jaeger, TF. That indicates anticipated production difficulty: Evidence from disfluencies; Paper presented at the Disfluency in Spontaneous Speech Workshop; Aix-en-Provence, France. 2005.

Jaeger, TF. Unpublished doctoral dissertation. Stanford, CA: Stanford University; 2006. Redundancy and syntactic reduction in spontaneous speech.

Jaeger TF. Categorical data analysis: Away from ANOVAs (transformation or not) and towards logit mixed models. Journal of Memory and Language. 2008; 59:434-446. [PubMed: 19884961]

Jaeger TF. Redundancy and reduction: Speakers manage syntactic information density. Cognitive Psychology. 2010; 61(1):23-62. [PubMed: 20434141]

Jaeger, TF. Corpus-based research on language production: Information density and reducible subject relatives. In: Bender, EM.; Arnold, JE., editors. Language from a Cognitive Perspective: Grammar, Usage, and Processing. Studies in honor of Tom Wasow. Stanford, CA: CSLI Publications; 2011. p. 161-197.

Keppel G, Underwood BJ. Proactive inhibition in short-term retention of single items. Journal of Verbal Learning \& Verbal Behavior. 1962; 1:153-161.

Kraljic T, Brennan SE. Prosodic disambiguation of syntactic structure: For the speaker or for the addressee? Cognitive Psychology. 2005; 50:194-231. [PubMed: 15680144]

Lee M-W, Gibbons J. Rhythmic alternation and the optional complementiser in English: New evidence of phonological influence on grammatical encoding. Cognition. 2007; 105:446-456. [PubMed: 17097626]

Levy, R.; Jaeger, TF. Speakers optimize information density through syntactic reduction. In: Schlökopf, B.; Platt, J.; Hoffman, T., editors. Advances in neural information processing systems (NIPS). Vol. 19. Cambridge, MA: MIT Press; 2007. p. 849-856.

Loftus GR, Masson MEJ. Using confidence intervals in within-subject designs. Psychonomic Bulletin \& Review. 1994; 1:476-490. [PubMed: 24203555]

Lombardi L, Potter MC. The regeneration of syntax in short term memory. Journal of Memory and Language. 1992; 31:713-733.

Masson MEJ, Loftus GR. Using confidence intervals for graphically based data interpretation. Canadian Journal of Experimental Psychology. 2003; 57:203-220. [PubMed: 14596478]

McRae K, Spivey-Knowlton M, Tanenhaus MK. Modeling the influence of thematic fit (and other constraints) in on-line sentence comprehension. Journal of Memory \& Language. 1998; 38:283312.

Oldfield RC, Wingfield A. The time it takes to name an object. Nature. $1964 ; 202: 1031-1032$. [PubMed: 14197320] 
Resnik P. Selectional constraints: An information-theoretic model and its computational realization. Cognition. 1996; 61:127-159. [PubMed: 8990970]

Roland DW, Dick F, Elman JL. Frequency of basic English grammatical structure: A corpus analysis. Journal of Memory and Language. 2007; 57:348-379. [PubMed: 19668599]

Sachs JS. Recognition memory for syntactic and semantic aspects of connected discourse. Perception \& Psychophysics. 1967; 2:437-442.

Snedeker J, Trueswell JC. Using prosody to avoid ambiguity: Effects of speaker awareness and referential context. Journal of Memory \& Language. 2003; 48(1):103-130.

Svartvik, J. On voice in the English verb. The Hague: Mouton; 1966.

Tannenbaum PH, Williams F. Generation of active and passive sentences as a function of subject or object focus. Journal of Verbal Learning and Verbal Behavior. 1968; 7:246-250.

Temperley D. Ambiguity avoidance in English relative clauses. Language. 2003; 79:464-484.

Thompson SA, Mulac A. The discourse conditions for the use of the complementizer that in conversational English. Journal of Pragmatics. 1991; 15:237-251.

Trueswell JC, Tanenhaus MK, Kello C. Verb-specific constraints in sentence procesing: Separating effects of lexical preference from garden-paths. Journal of Experimental Psychology: Learning, Memory, and Cognition. 1993; 19:528-553.

Wasow, T.; Jaeger, TF.; Orr, D. Lexical variation in relativizer frequency. In: Simon, H.; Wiese, H., editors. Proceedings of the 2005 DGfS Workshop "Expecting the Unexpected: Exceptions in Grammar. Berlin/New York: Mouton de Gruyter; 2011.

Yaguchi M. The function of the non-deictic that in English. Journal of Pragmatics. 2001; 33(7):11251155. 


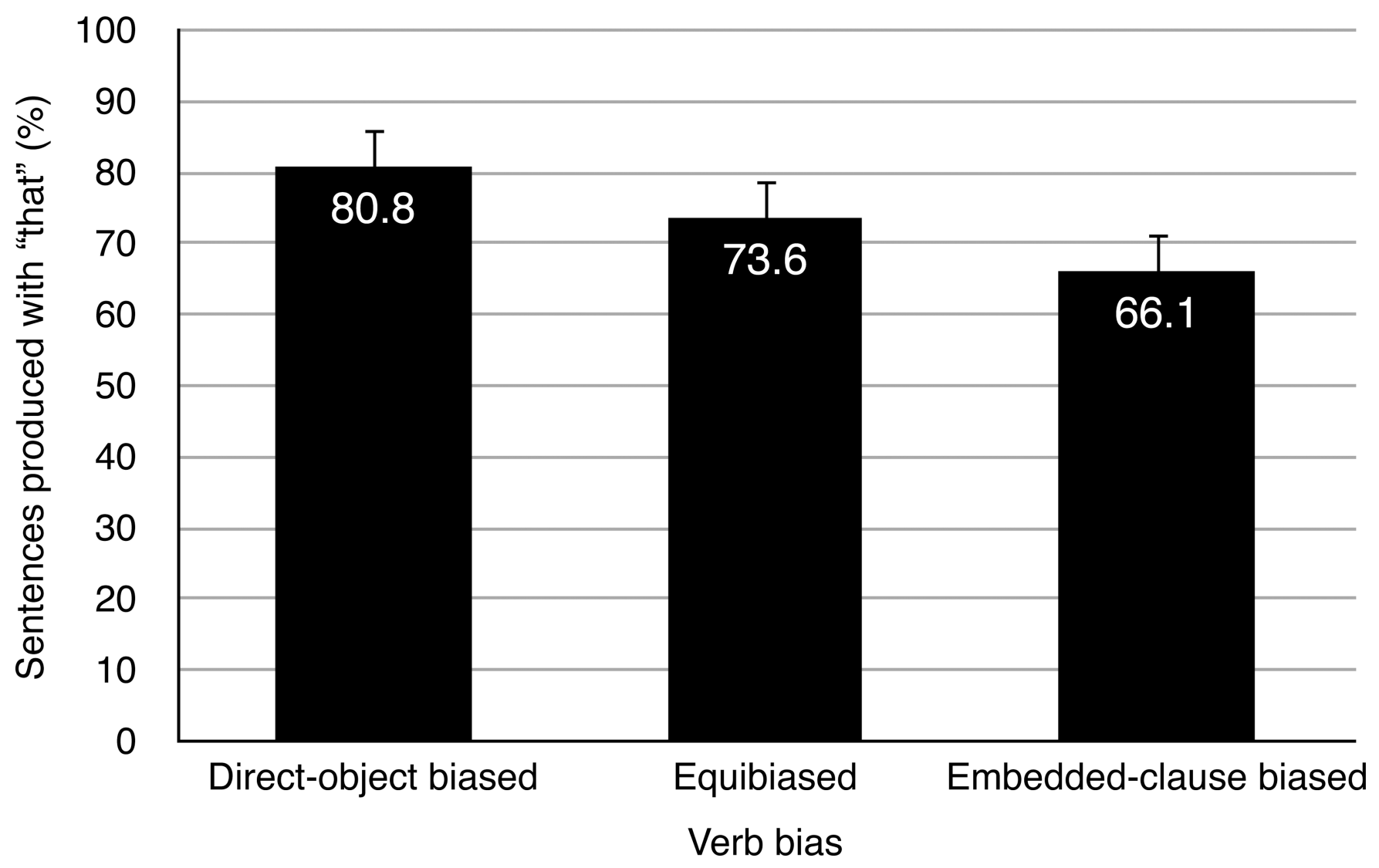

Figure 1.

Experiment 1 results. Percentages of "that" produced in sentence-complement structures with direct-object biased, equibiased, and embedded-clause biased verbs. Error bars show 95\% confidence interval halfwidth for the main effect of verb type. 


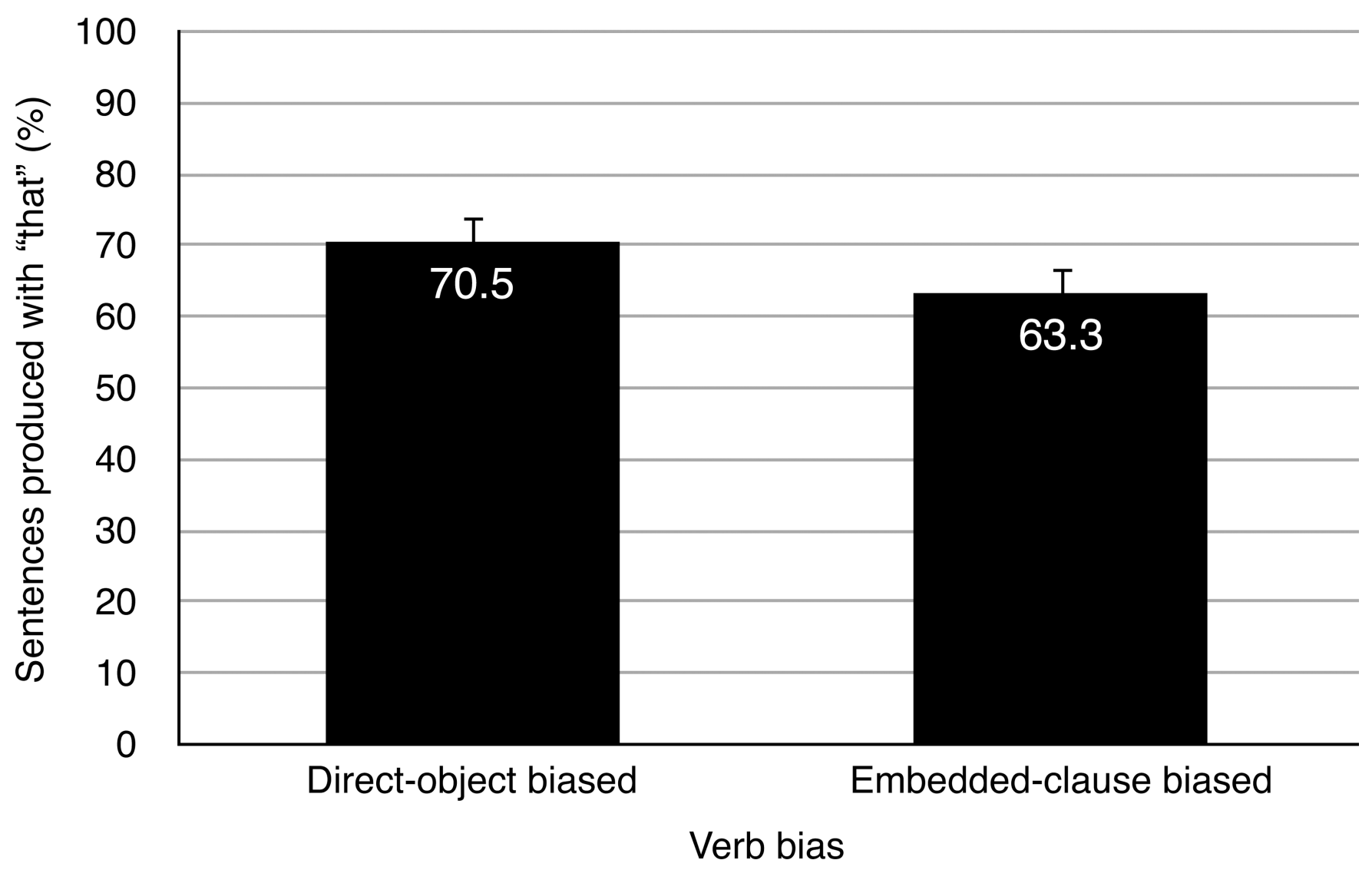

Figure 2.

Experiment 2 results. Percentages of "that" produced in sentence-complement structures with direct-object biased and embedded-clause biased verbs. Error bars show $95 \%$ confidence interval halfwidth for the main effect of verb type. 


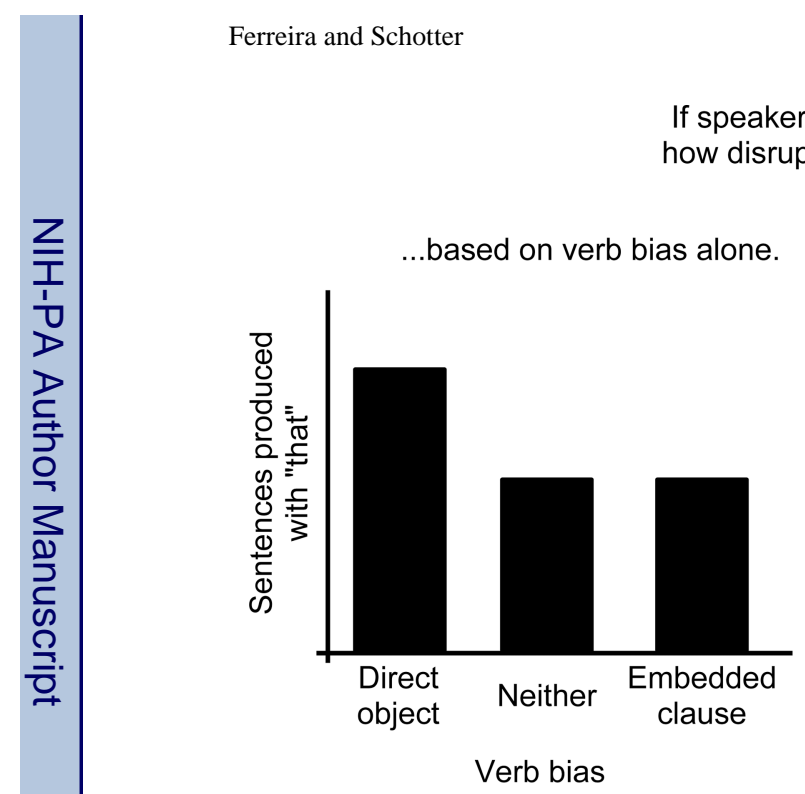

(a)
If speakers are sensitive to how disruptive garden paths are...

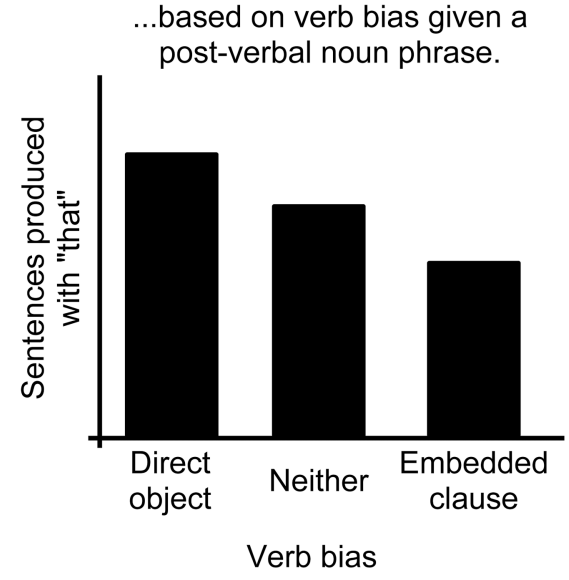

(b)

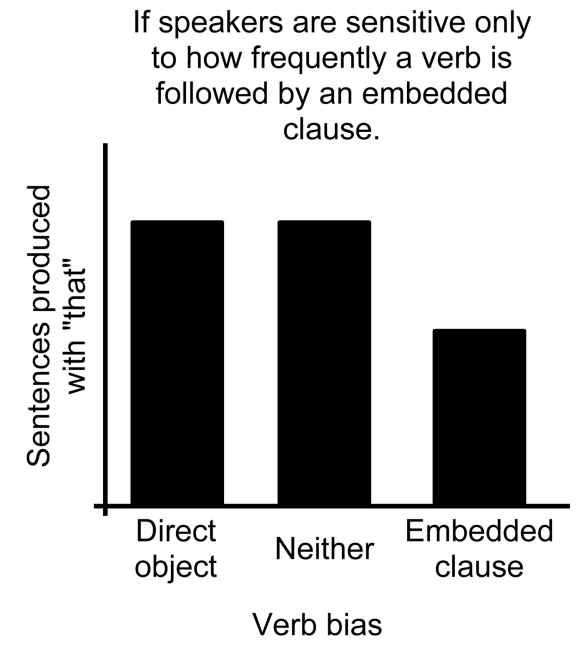

(c)

Figure 3.

Predicted percentages of "that" produced in sentence-complement structures with directobject biased, neither-biased, and embedded-clause biased verbs for Experiment 3 a. 


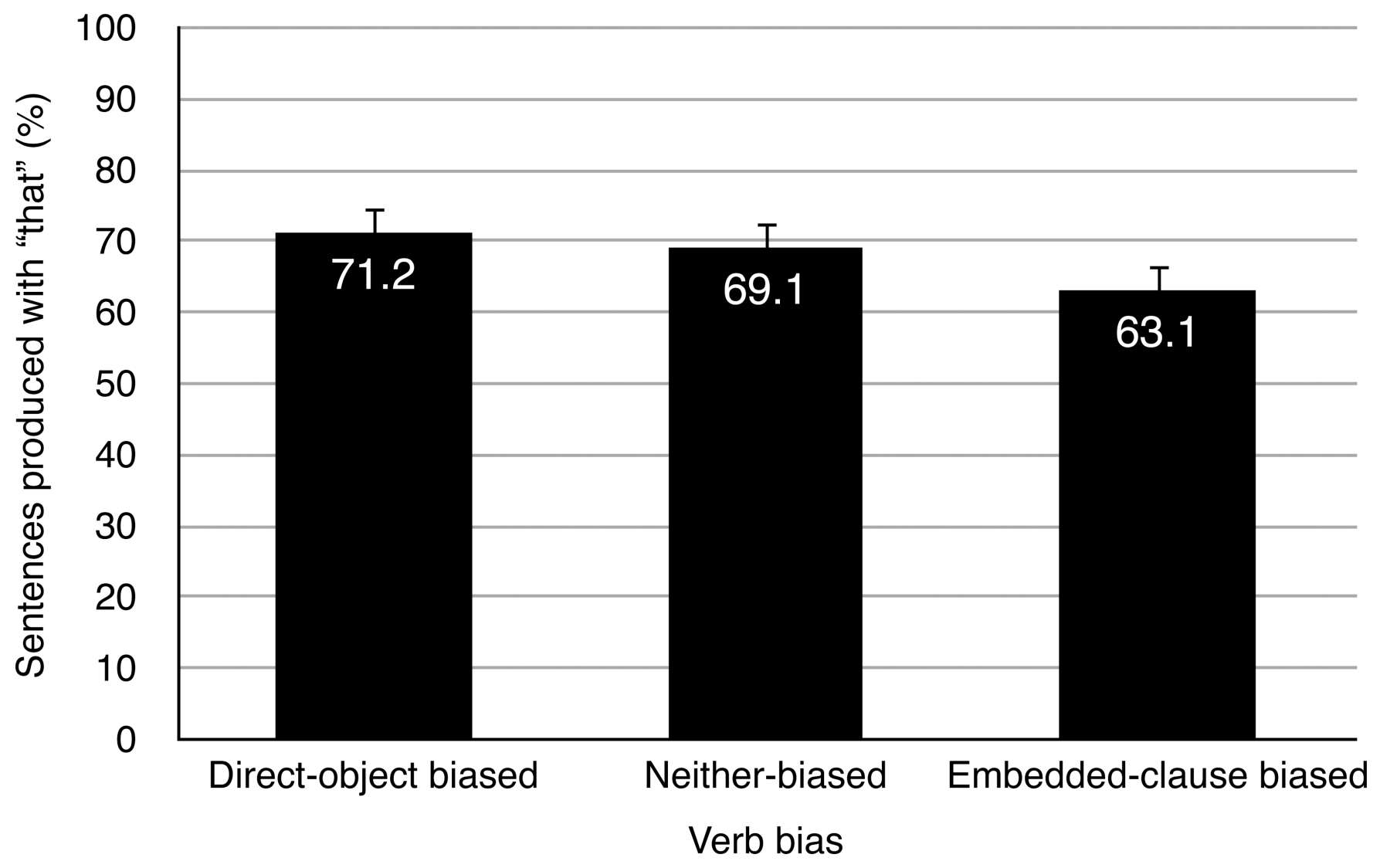

Figure 4.

Experiment 3a results. Percentages of "that" produced in sentence-complement structures with direct-object biased, neither-biased, and embedded-clause biased verbs. Error bars show $95 \%$ confidence interval halfwidth for the main effect of verb type. 

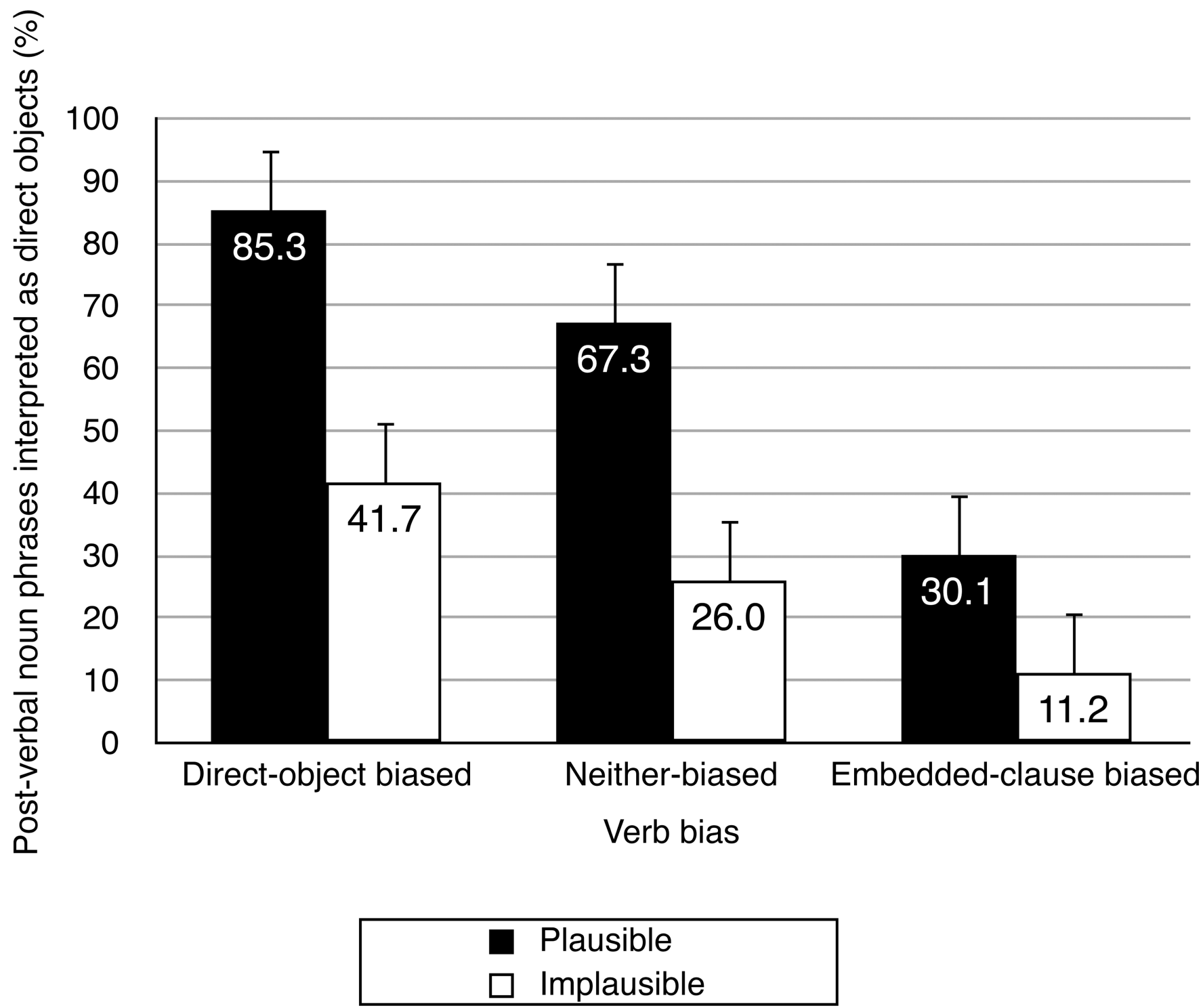

Figure 5.

Experiment $3 \mathrm{~b}$ results. Percentages of post-verbal noun phrases interpreted as direct objects with main verbs that are direct-object biased, neither-biased, and embedded-clause biased, and when post-verbal noun phrases were plausible or implausible as direct objects. Error bars show $95 \%$ confidence interval halfwidth for the plotted interaction effect. 


\section{Table 1}

Examples of sentences used in Experiment 1

\begin{tabular}{llcc}
\hline Verb type & Example sentence & $\begin{array}{c}\text { Direct-object } \\
\text { continuations } \\
(\boldsymbol{\%})\end{array}$ & $\begin{array}{c}\text { Embedded } \\
\text { clause } \\
\text { continuations } \\
(\mathbf{\%})\end{array}$ \\
\hline $\begin{array}{l}\text { Direct-object } \\
\text { biased }\end{array}$ & $\begin{array}{l}\text { The talented photographer accepted } \\
\text { (that) the money could not be spent yet. }\end{array}$ & 69.7 & 13.7 \\
$\begin{array}{l}\text { Equibiased } \\
\text { The weary traveler claimed (that) the } \\
\text { luggage had been stolen in Rome. }\end{array}$ & 35.3 & 36.1 \\
$\begin{array}{l}\text { Embedded clause } \\
\text { biased }\end{array}$ & $\begin{array}{l}\text { The proud mother announced (that) the } \\
\text { wedding would be a big event. }\end{array}$ & 11.8 & 58.7 \\
\hline
\end{tabular}

Note. Embedded clause continuations and direct-object continuations from normative data reported in Garnsey et al. (1997). 


\section{Table 2}

Experiment 1 results. Excluded trials and percentages of "that" produced in sentence complement structures with direct-object biased, equibiased, and embedded clause biased verbs when originally encoded sentences included or omitted "that."

\begin{tabular}{lcc}
\hline Experimental Condition & Excluded trials (\%) & "That" produced (\%) \\
\hline Originally encoded with "that" & 37.8 & 88.9 \\
Direct-object biased & 31.8 & 85.4 \\
Equibiased & 29.7 & 74.9 \\
Embedded clause biased & & \\
Originally encoded without "that" & 35.4 & 72.6 \\
Direct-object biased & 33.3 & 61.8 \\
Equibiased & 26.3 & 57.3 \\
Embedded clause biased & & \\
\hline
\end{tabular}




\section{Table 3}

Examples of sentences used in Experiment 2

\begin{tabular}{llccc}
\hline Verb type & Example sentence & $\begin{array}{c}\text { Direct-object } \\
\text { continuations } \\
(\boldsymbol{\%})\end{array}$ & $\begin{array}{c}\text { Embedded } \\
\text { clause } \\
\text { continuations } \\
\mathbf{( \% )}\end{array}$ & $\begin{array}{c}\text { Excluded } \\
\text { trials (\%) }\end{array}$ \\
\hline $\begin{array}{l}\text { Direct-object } \\
\text { biased }\end{array}$ & $\begin{array}{l}\text { The talented photographer accepted } \\
\text { (that) the money could not be spent yet. }\end{array}$ & 67.7 & 12.6 & 31.9 \\
$\begin{array}{l}\text { Embedded clause } \\
\text { biased }\end{array}$ & $\begin{array}{l}\text { The ticket agent admitted (that) the } \\
\text { mistake had been careless and stupid. }\end{array}$ & 10.2 & 57 & 21.3 \\
\hline
\end{tabular}

Note. Embedded clause continuations and direct-object continuations from normative data reported in Garnsey et al. (1997). 
